\title{
A Study on Social Media and Substance Abuse as Coping Mechanisms in Indian College Students
}

\author{
Nidah Merchant ${ }^{1}$, Fatima Tejani ${ }^{2}$, Khushali Adhiya-Shah ${ }^{3}$ \\ ${ }^{1,2}$ Undergraduate Students, ${ }^{3}$ Assistant Professor \\ Department of Psychology, Mithibai College of Arts, Science \& Commerce, Mumbai. \\ Corresponding author: Mrs. Khushali Adhiya-Shah \\ Email - khushali.adhiyashah@gmail.com
}

\begin{abstract}
Background: Increasing perceived stress directs college students to resort to a variety of coping mechanisms. Among the popular strategies, many college students are reaching out to social media, while many take to substance abuse. Like two sides of a coin, substance abuse and social media are used for both negative and positive purposes. The present study is designed to explore which coping mechanism substance abuse or social media, do young adults employ to cope with their stress and the effectiveness of that mechanism.

Methods: A sample of 167 male and female college students is selected. Data is collected through a selfdesigned questionnaire and Index of Clinical Stress (Abell, 1991). Descriptive statistics, student's t-test and ANOVA is employed to analyse the data.

Results: Results indicate no significant differences in the perceived stress experienced by students who use social media, substance abuse and both as coping mechanisms. More students using social media as coping measure reported a decrease in their stress. Also, students who perceived social support reported the least stress experienced. Dissatisfaction with their choice of coping measure also reported higher stress in the students. Almost half the sample reported that they would recommend neither social media nor substance abuse as coping mechanisms.

Conclusion:The results guide towards numerous future research ideas, as none of the two coping mechanisms seem to relieve stress in young adolescents and they do not qualify to be recommended. The importance of social support and satisfaction with one's own choices is reiterated.
\end{abstract}

Keywords: Stress, Coping mechanism, College students, Social media, Substance abuse.

(Paper received $-5^{\text {th }}$ January 2018, Peer review completed $-12^{\text {th }}$ January 2018)

(Accepted $-16^{\text {th }}$ January 2017)

\section{INTRODUCTION}

Stress and coping, as variables, have been conceptualized in a number of ways by different authors and researchers. Some have formulated stress as a response to a perceived stressful situation, while others suggest stress is a stimulus in itself. Eventually, it is the individual's subjective appraisal of the stress that decides his/her response to it -coping [1].

An idea initially explored by Walter Cannon, stress as a concept was popularized by Hans Selye. Following Selye, several papers and theories have been published relating stress to various physiological and psychological factors. Considering the way stress is perceived and experienced, coping follows. Folkman and Lazarus say that coping is influenced by an individual's cognitive appraisal of an event, which subsequently influences emotional arousal. So, copingimplies a more specific process of cognitive appraisal to determine whether an individual believes he or she has the resources to respond effectively to 
the challenges of a stressor or change. The response for coping process can be in terms of problem-focused coping or emotion-focused coping [2].

Among the presently popular coping mechanisms, social media has become an integral part college students' life. While, it has various negative outcomes that aim the self-worth of the college students, social media has various positive outcomes too- many have found support in various online communities, healing, strength, friendship, and love they long for. Shaw and Gant found that internet use decreased loneliness and depression significantly, while perceived social support and self-esteem increased significantly. The usage of social networking has brought lots of changes in interpersonal relationships between students and members of family; it also helped students to have more communication with their family members and friends [3].

While some people manage to find healthy ways of coping with stress, substance abuse is also increasingly being used as a means to cope with stress - use of drugs, smoking and alcohol. Palmer and his team report that substance abuse is mostly used to cope with difficult emotions, challenging life events, death of a family member, a break-up, illness, etc., boredom, stress, insomnia, trauma / PTSD, social anxiety, etc. $69 \%$ college students who self-reported lifetime use of an illicit drug reported at least one negative consequence over the course of their lifetime; $28 \%$ of them reported being moderately concerned about their drug or medication misuse and moderately interested in some form of intervention. Unfortunately, as a coping mechanism, the temporary benefits are outweighed by the long-term negative effects on health and relationships, poor decision-making under the influence, as well as increased dependency [4]. In recent years, authors have reported saying that prescription drug misuse has become increasingly prevalent among college students and has been related to poorer academic performance and high-risk behaviour [56].

The present study aims at exploring the use of social media and substance abuse specifically as coping measures. The objective is to understand the differential implication of these coping alternatives and explore a direction for future research in the area of coping.

It is hypothesized that:

(a) There will be no significant difference in the number of college students who employ social media and substance abuse as their coping mechanism.

(b) There will be no significant difference in the stress perceived by those who use social media and substance abuse as coping strategies.

\section{METHODOLOGY}

\section{Sample}

A random sample of 170 college students were employed, aged 17 - 25 years old, for the study (27 males, 143 females; mean age 19 years; SD 1.061). The participants belonged to middle and upper socioeconomic strata and had no prior experience of the tools employed for data collection.

\section{Procedure}

An online survey method was employed comprising of two scales. A questionnaire was designed comprising of 12 self-report behaviour questions. The Index of Clinical Stress was also administered to measure the perceived clinical stress of participants. Ethical mandates of informed consent, voluntary participation and confidentiality were followed.

\section{Instruments}

- Index of Clinical Stress [7]: This is a 25 items self-report questionnaire administered on individual adults, over 12 years of age. A low score indicates relative absence of the problem being measured. The reliability alpha of the scale is 0.90 , revealing the scale's good internal consistency.

- A questionnaire was designed to explore the usage of substance abuse and social media as coping measures.

\section{Statistical Analysis}

Descriptive statistics, student's $t$ and ANOVA analysis were carried out using the SPSS statistical software program (version 16.0) (SPSS, 2008). 


\section{RESULTS \& DISCUSSION}

Among the several coping strategies that have been compared and proven for effectiveness by several studies, use of substance abuse and social media individually is the objective of this study.

Table 1 and Figure 1 suggest that only $2(1.2 \%)$ participants admitted their use of substance abuse as a coping mechanism, in comparison to $151(90.42 \%)$ who reported reliance on social media. Rejecting our first hypothesis, the probable reason of such a finding could be identified as social media being readily and easily accessible and convenient to college students as opposed to substances like alcohol, drugs, tobacco, etc. Further, 14 (8.38\%) college students reported using both social media and substance abuse as strategies to cope with stress. Molly O'Toole [8] reported 70\% of teenagers spend hours on Facebook, Myspace and other social networking sites. For this same age bracket, social-network-savvy teens are five times more likely to use tobacco; three times more likely to use alcohol; and twice as likely to use marijuana than teens who do not spend any of their day on social networking sites. Therefore, it is possible that use of one reinforces the use of another.

Table 1: Number college students who employ either social media or substance abuse or both as their coping mechanism.

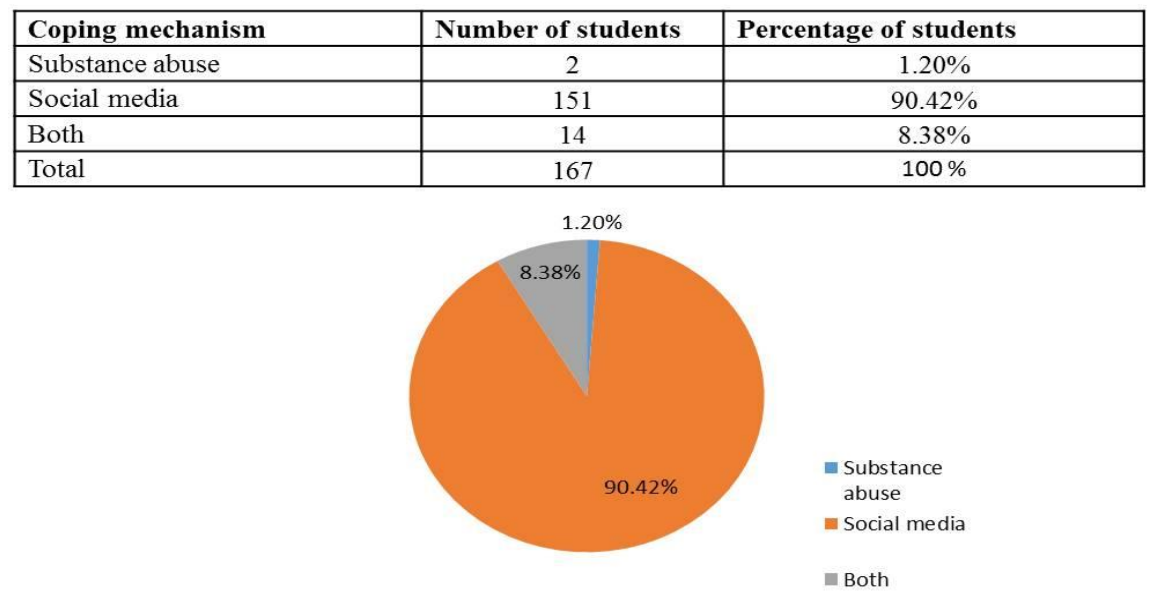

Figure 1: Coping strategies used by college students

Table $2 \mathrm{t}$-test results suggest a significant difference between the two self report forms of perceived stress a direct question and a standardised clinical stress scale $(t=7.443, p<0.0001)$, with a larger group mean in the self report of perceived stress (2.62) than the standardized clinical stress scale (2.14). The finding hints at the disadvantage of asking college students about their experienced stress directly for they may exaggerate their experience and report higher stress, while a standardized scale accounts for this concern.

On exploring the difference in the clinical stress levels between those employing substance abuse, social media and both as coping measures, the results indicate non-significant differences on the analysis of variance test $(f=0.595, p>0.05)$. Therefore, irrespective of the coping measure employed, the stress levels perceived by participants do not significantly differ from the other participants. Multiple comparisons also suggest no significant differences between any of the three groups.

Accepting our second hypothesis, this finding proposes that neither of the coping measures have proven their effectiveness in reducing the perceived stress levels of college students. Das and others reported the prevalence of many unhealthy behaviours beginning in adolescence, and that substance abuse has had grave impact on individuals, families and communities [9]. It is important to note that individual and family factors can be important factors of substance abuse [10]. Several studies have reported an extensive analysis of the $\mathrm{r}$ impact, risk factors and prevalence of substance abuse in India [11]. Similarly, the impact of social media among the Indian youth has also been extensively researched, more than often examining 
the negative outcomes [12-14]. It is, therefore, imperative that healthier coping alternatives be made visible and available to college students in our country.

One possible confound of this result could be accounted to the unequal sample size between the social media and substance abuse user groups. It can be highlighted that from a sample of 167 participants, only 2 reported their dependence on substance as a coping measure. This could be interpreted in multiple ways - one, in our Indian settings, admitting the use of substance is low; two, substance users in the random sample is less; three, it is possible that the 15 participants reporting the use of both social media and substance abuse are substance abusers and wish to mask their dependence on solely the latter.

$13(8.61 \%)$ students reported various other consequences of using social media to cope with stress, such as diverting their mind away from stress and moderate or temporary reduction of stress. This implies that social media does help college students to reduce stress to some extent. One way to explain this is that through social media people may realize that problems are universal by connecting with similar people. Also, the various online communities support and help young students to cope with stress effectively. Several studies have reported positive impact of social media on mental health, such as decrease in loneliness and depression and find that time on the Internet was positively associated with communication, social involvement, and overall well-being.

Further Figure $2 b$ denotes the reported consequence of substance abuse as a coping mechanism. In our random sample, only 2 participants out of 167 , have voluntarily reported their use substance to cope with stress, from which 1 indicated that it helps to reduce stress while the other was not aware of any effect that substance abuse had on stress. However, it would not be appropriate to compare the effectiveness of social media and substance abuse as a coping mechanism due to unequal sample size.

Significant differences on the analysis of variance test $(\mathrm{f}=3.830, \mathrm{p}<0.005)$, indicate that perceived stress levels differ with difference in social support they receive, with the largest group mean(57.81) of students who never perceive social support around when they need while it was the smallest (36.71) for those who always perceive social support. This clearly suggests that as more social support is perceived by college students, their perceived stress level decreases. Multiple comparisons show significant difference between those who always and those who never perceive social support $(\mathrm{p}=0.009)$, and between students who never and often perceive it when needed $(\mathrm{p}=0.019)$.

Numerous studies support that social support is essential for maintaining physical and psychological health. Baqutayan [15] found that students who reported less social support reported more stress. Hispanic students who perceived that social support was available had lower distress ratings than students who perceived social support was less available, and social support was found to moderate the relationship between stress and distress. Lack of social support might also lead to maladaptive behaviours which further add to stress. A recent study found that students who perceived less social support from friends reported higher amounts of alcohol use [16].

Significant differences on the analysis of variance test $(\mathrm{f}=3.702, \mathrm{p}<0.027)$ indicates a difference between individuals perceiving stress levels as a function of their satisfaction with their coping mechanism, with group mean being highest for those who report dissatisfaction with their coping mechanism (47.60) followed by those who are not sure about whether the coping mechanism they employ is effective (40.96).Further, the group mean was lowest for those college students reported satisfaction with their coping mechanism (38.36). Multiple comparisons also suggest significant differences between those who report satisfaction and those who report dissatisfaction with the mechanism they adopt to cope with stress $(p=0.28)$. It can be concluded that satisfaction with the employed coping mechanism plays an important role in perceived stress levels. Also, such specific comparisons are less reported in Indian scientific literature.

Figure 3 highlights the coping mechanisms that students reported they would recommend to others. It was observed that out of 167 college students, $36(21.55 \%)$ participants would suggest social media as a coping mechanism to others whereas only $3(1.80 \%)$ participants recommended substance abuse to others.However, it is important to note that majority of 83 (49.70\%) participants preferred not to suggest any coping mechanism. Also, $45(26.95 \%)$ participants suggested recommending various others mechanisms to cope with stress which included engaging in physical activities, yoga, meditation, etc. 


\section{Strengths and Limitations}

An exploration into two specific coping mechanisms in an Indian college sample is one of the strengths of this study. The results guide towards numerous future research ideas, as none of the two coping mechanisms seem to relieve stress in young adolescents and they do not qualify to be recommended. The importance of social support and satisfaction with one's own choices is reiterated.

However, an unequal randomized sample size between social media and substance users poses concern. Limitations of an online and survey method, in addition to mood, peer pressure, etc. confounds the results.

\section{Implications for future studies}

Findings of the study indicate that the Indian college students need healthier coping alternatives in mainly their academic and social perceived stress. Neither of the coping mechanisms seems to reduce stress nor are they satisfactory enough to be recommended to others. They need more availability and support of mental health practitioners and other beneficial coping measures such as music therapy, animal-assisted therapy and bibliotherapy. Considering the possibilities, this research suggests the further exploration of this concern as future research implications.

\section{REFERENCES}

1. Kadison R, DiGeronimo TF. College of the overwhelmed: The campus mental health crisis and what to do about it. Jossey-Bass; 2004.

2. Voelker R. Stress, sleep loss, and substance abuse create potent recipe for college depression. JAMA 2004;291(18):2177-9.

3. Das JK, Salam RA, Arshad A, Finkelstein Y, Bhutta ZA. Interventions for adolescent substance abuse: An overview of systematic reviews. J Adolesc Health 2016;59(4):S61-75.

4. Unger JB, Baezconde-Garbanati L, Shakib S, Palmer PH, Nezami E, Mora J. A cultural psychology approach to drug abuse prevention. Subst Use Misuse 2004;39(10-12):1779-820.

5. Amaro H, Blake SM, Schwartz PM, Flinchbaugh LJ. Developing theory-based substance abuse prevention programs for young adolescent girls. J Early Adolesc 2001;21(3):256-93.

6. McCabe SE, Bostwick WB, Hughes TL, West BT, Boyd CJ. The relationship between discrimination and substance use disorders among lesbian, gay, and bisexual adults in the United States. Am J Public Health 2010;100(10):1946-52.

7. Abell N. The Index of Clinical Stress: A brief measure of subjective stress for practice and research. Soc Work Res Abstracts 1991;27(2):12-5.

8. O’Toole BI, Marshall RP, Schureck RJ, Dobson M. Posttraumatic stress disorder and comorbidity in Australian Vietnam veterans: risk factors, chronicity and combat. Austr NZ J Psychiatry 1998;32(1):32-42.

9. Didarloo A, Pourali R. University Students' Views Regarding Reasons for Drug Abuse Among Youths. Int J High Risk Behav Addictions 2016;5(1)106-9.

10. Murthy P, Manjunatha N, Subodh BN, Chand PK, Benegal V. Substance use and addiction research in India. Indian J Psychiatry 2010;52(Supp11):S189-96.

11. Chakravarthy B, Shah S, Lotfipour S. Adolescent drug abuse-Awareness \& prevention. Ind J Med Res 2013;137(6):1021-5.

12. Siddiqui $\mathrm{S}$, Singh T. Social Media its Impact with Positive and Negative Aspects. International Journal of Computer Applications Technology and Research. 2016;5(2):71-5.

13. Ahuja R, Bharadwaj A. Impact of Social Networking Sites on Indian Youth: Boon or Bane?. The Int J Indian Psychol 2016:4(1):74-8.

14. Bhardwaj A, Avasthi V, Goundar S. Impact of Social Networking on Indian Youth-A Survey. International Journal of Electronics and Information Engineering 2017;7(1):41-51.

15. Baqutayan SM, Mai MM. Stress, strain and coping mechanisms: An experimental study of fresh college students. Academy of Educational Leadership Journal 2012;16(1):19-23.

16. Madruga CS, Laranjeira R, Caetano R, Pinsky I, Zaleski M, Ferri CP. Use of licit and illicit substances among adolescents in Brazil—a national survey. Addict Behav 2012;37(10):1171-5. 
TABLE 2: shows differences between self report of perceived stress in the questionnaire and perceived stress as reported in the standardized clinical stress scale.

\begin{tabular}{|c|c|c|c|c|c|}
\hline \multicolumn{6}{|c|}{ Paired Samples Statistics } \\
\hline & & Mean & $\mathrm{N}$ & Std. Deviation & $\begin{array}{l}\text { Std. Error } \\
\text { Mean }\end{array}$ \\
\hline \multirow[t]{2}{*}{ Pair 1} & SSR & 2.62 & 167 & .909 & .070 \\
\hline & ICS & 2.14 & 167 & .950 & .074 \\
\hline
\end{tabular}

Paired Samples Correlations

\begin{tabular}{|ll|r|r|r|}
\hline & \multicolumn{1}{|c|}{$N$} & Correlation & Sig. \\
\hline Pair 1 SSR \& ICS & 167 & .591 & .000 \\
\hline
\end{tabular}

Paired Samples Test

\begin{tabular}{|c|c|c|c|c|c|c|c|c|}
\hline & \multicolumn{5}{|c|}{ Paired Differences } & \multirow[b]{3}{*}{$t$} & \multirow[b]{3}{*}{ df } & \multirow[b]{3}{*}{ Sig. (2-tailed) } \\
\hline & \multirow[b]{2}{*}{ Mean } & \multirow[b]{2}{*}{ Std. Deviation } & \multirow{2}{*}{$\begin{array}{l}\text { Std. Error } \\
\text { Mean }\end{array}$} & \multicolumn{2}{|c|}{$\begin{array}{l}\text { 95\% Confidence Interval of the } \\
\text { Difference }\end{array}$} & & & \\
\hline & & & & Lower & Upper & & & \\
\hline Pair 1 SSR - ICS & .485 & .842 & .065 & .356 & .614 & 7.443 & 166 & .000 \\
\hline
\end{tabular}

Table 4a: Reported effect of using social media as a way to cope with stress.

\begin{tabular}{|l|c|c|}
\hline CONSEQUENCE & $\begin{array}{l}\text { No. of } \\
\text { students }\end{array}$ & $\begin{array}{l}\text { Percentage of } \\
\text { students }\end{array}$ \\
\hline REDUCES STRESS & 47 & $31.12 \%$ \\
\hline INCREASES STRESS & 11 & $7.29 \%$ \\
\hline DON'T KNOW & 34 & $22.52 \%$ \\
\hline NO DIFFERENCE & 41 & $27.15 \%$ \\
\hline OTHERS & 13 & $8.61 \%$ \\
\hline
\end{tabular}

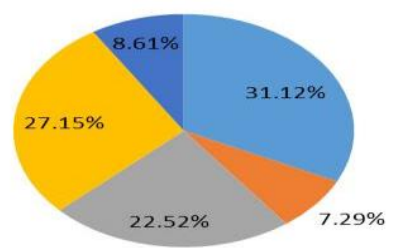

$$
\begin{aligned}
& =\text { REDUCES STRESS } \\
& =\text { INCREASES STRESS } \\
& =\text { DON'T KNOW } \\
& =\text { NO DIFFERENCE } \\
& =\text { OTHERS }
\end{aligned}
$$

Figure 2a: Reported consequence of using social media as a stress coping mechanism.

Table 4b: Reported consequence of using substance as a way to cope with stress.

\begin{tabular}{|l|c|c|}
\hline CONSEQUENCE & No. of students & $\begin{array}{c}\text { Percentage of } \\
\text { students }\end{array}$ \\
\hline $\begin{array}{l}\text { REDUCES } \\
\text { STRESS }\end{array}$ & 1 & $50 \%$ \\
\hline DON'T KNOW & 1 & $50 \%$ \\
\hline
\end{tabular}

Table 7: Coping mechanisms that college students would recommend to others.

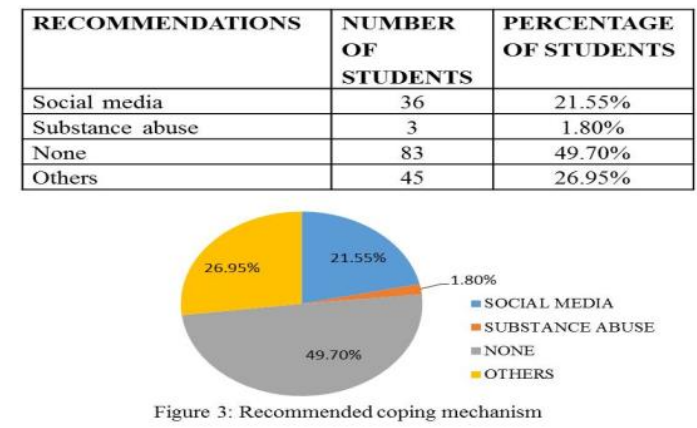

Indian Journal of Mental Health 2018;5(1) 